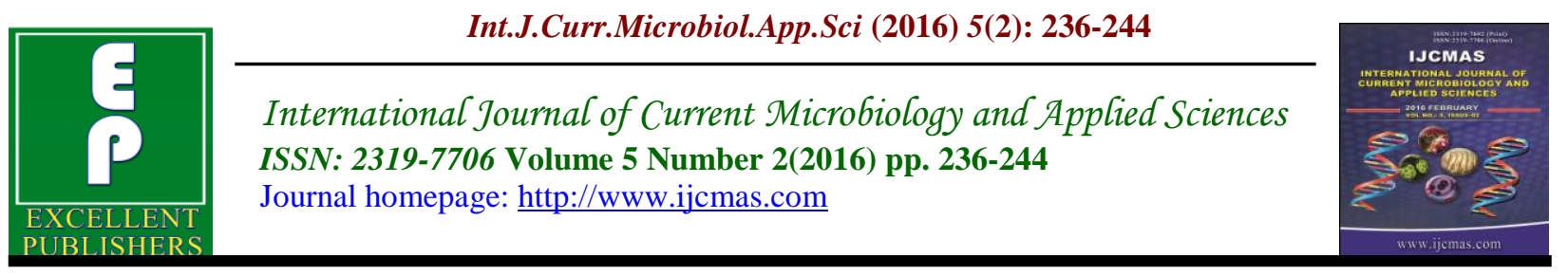

Original Research Article

doi: http://dx.doi.org/10.20546/ijcmas.2016.502.026

\title{
Antifungal Activity of Solanum xantocarpum Sch and Wend and Picrorhiza kurroa Royle ex Benth against Some Clinical Dermatophytes
}

\author{
K. S. Shubha ${ }^{1^{*}}$, K. Sumana ${ }^{2}$ and L. Lakshmidevi ${ }^{1}$ \\ ${ }^{1}$ DOS in Microbiology, University of Mysore, Mysore, India \\ ${ }^{2}$ Faculty of Life Sciences, Microbiology Division, JSS University, Mysuru, India \\ *Corresponding author
}

Keywords

Solanum

xantocarpum

(root \& fruit),

Picrorhiza

kurroa rhizome),

Article Info

Accepted:

14 January 2016

Available Online:

10, February 2016

\section{A B S T R A C T}

\section{Introduction}

In India, Ayurveda system evolved over 5,000 years ago and is still in practice. The Rig Veda and Atharvana Veda have included more than 700 medicinal prescriptions (Mnimh, 1996). Others systems of medicine such as Chinese, Unani and Siddha traditions have their roots in Ayurveda. All the medicinal system is mostly based on the plant and its products that are available in Indian medicine. These have household remedies (Yadav and Kumar, 2003). The use of plants and its products has a long history that began with folk medicine and through the years it has been incorporated into traditional and allopathic medicine (Dubey et al., 2011).

The World Health Organization (WHO) estimated that about an $80 \%$ population of developing countries relies on traditional medicines, mostly plant drugs for their primary health care needs (WHO, 2008). Particularly in rural India, uses of raw plant products as well as some concoction of Ayurvedic medicines are sought after to a great proportion, because of cheap availability, and in urban areas too these are popular (Tuley et al., 2009). Despite the 
advent of modernism in medicinal system in the $21^{\text {st }}$ century, poverty stricken and marginalized aborigine-folks (tribal's) of India, living in forest patches, particularly, are still practicing the art of the use of crude herbal products as medicines (Ignacimuthu et al., 2008; Panda and Panda, 2008; Prasad et al., 2008; Singh and Singh, 2009). In tribal- India, the clandestine knowledge of medicinal plants and their uses are transmitted down the generations, which sometimes, becomes a risky.

It has been estimated that in the Indian subcontinent, about 45,000 species of medicinal plants are used in tribal health care needs, and only about 1,500 plants are in use in Indian Ayurveda, Unani and Siddha System, largely for elite mass (Tuley et al., 2009). Since antiquity, many plants species are reported to have pharmacological properties as they are known to posses various secondary metabolites like glycosides, saponins, flavonoids, steroids, tannins, alkaloids, tripenes which can therefore, be utilized to combat the disease causing pathogens (Kamali and Amir, 2010; Lalitha et al., 2010; Hussain et al., 2011).

Infectious diseases represent a critical problem to health and they are one of the main causes of morbidity and mortality worldwide (WHO, 1998). During the past several years, there has been an increasing incidence of fungal infections due to a growth in immunocompromised population such as organ transplant recipients, cancer and HIV/AIDS patients. This fact coupled with the resistance to antibiotics and with the toxicity during prolonged treatment with several antifungal drugs (Giordani et al., 2001). This has been the reason for an extended search for newer drugs to treat opportunistic fungal infections in immunosuppressed patients (Fostel and Lartey, 2000).

\section{Materials and Methods}

Fresh disease free root and fruit of $S$. xantocarpum. Sch \& Wend were collected in and around the Mysore district, Karanataka, India. They were washed thoroughly 2-3 times with running water and once with sterile water, and dried in shade. Rhizome of P. kurroa. Royle ex Benth was obtained from the Himalayan drug Company, Bangalore. The Taxonomic identification of these two plants species was determined at National Ayurved Dietetics Research Institute, Bangalore, Karanataka, India. (S. xantocarpum Sch \& Wend. Voucher no. RRCBI-3721 and $P$. kurroa Royal ex Benth Voucher no. RRCBI/Mus-117). Both the plant materials were powered to $100-120$ mesh in an apex grinder (Apex constructions, London) and stored in air tight bottles.

\section{Test Microorganism}

The clinical isolates viz., Candida albicans, Candida tropicalis, Trichophyton rubrum, Penecillium marneffi were obtained from Department of Microbiology, Mysore Medical College, Mysore. The fungal cultures were maintained on Seaboards Dextrose Agar (SDA).

\section{Preparation of Solvent Extract}

Twenty grams of the powered plant viz., fruit of $S$. xantocarpum was loaded in the thimble of Soxhlet apparatus. It was fitted with appropriate round bottom flask and the plant material was extracted with $150 \mathrm{ml}$ alcohol (Merck, Darmstadt) (Khan et al., 1988). Constant heat was provided by Mantox heater for recycling the solvent. After complete extraction, the extract in the round bottom flask was transferred into sterile dry Petri plate and solvent was evaporated. The sediments was scrapped off, weighed and dissolved in Dimethyl sulfoxide (DMSO) solution and tested for 
antifungal activity. The same procedure was adopted for the remaining plant materials i.e. root of $S$. xanthocarpum and rhizome of $P$. kurroa.

\section{Antifungal Screening by Poisoned Food Technique}

SDA was amended with the alcohol extracts (mother extracts) to make $5 \%$ and $10 \%$ concentrations. The solidified agar plates in triplicates were inoculated at the centre with $5 \mathrm{~mm}$ diameter mycelia disc of the pathogen viz., C.albicans, C.tropicalis, T.rubrum, and P.marneffi. The Petri plates were incubated at $27 \pm 1^{\circ} \mathrm{C}$ for seven days. The plates without extract served as control (Nene and Thapliyal, 1979). The colony diameter was measured and percent inhibition of radial growth was calculated by using the formula given by Vincent (1927).

$\mathrm{I}=\mathrm{C}-\mathrm{T} / \mathrm{C} \times 100$

Where, I-percent inhibition

C-Colony diameter in control

$\mathrm{T}$ - Colony diameter in treatment

\section{Results and Discussion}

Alcoholic extracts of the plants tested in the present study has shown the significant antifungal activity but the inhibition of the dermatophytic fungi is found to be varied with respect to the specific plant extract.

\section{Ethanol Extract of S. xantocarpum Root}

$5 \%$ extract showed $70 \%$ inhibition of
C.albicans followed by $32.14 \%$ of C.tropicalis and $25 \%$ of P.marneffi and T.rubrum showed least of $15.4 \%$ inhibition. Where as in $10 \%$ extract exhibited maximum inhibition of C.albicans by $75 \%$ and moderately C.tropicalis, T.rubrum and least with P.marneffi by $46.4 \%, 46.2 \%$ and $33.3 \%$ respectively. Table (1), Fig 1.

\section{Ethanol Extract of S. xantocarpum Fruit}

$5 \%$ extract inhibited C.albicans by $72.5 \%$ moderately inhibited P.marneffi by $41.66 \%$ and least inhibition was observed in T.rubrum and C.tropicalis by $38.46 \%$ and $28.7 \%$ respectively. However in $10 \%$ solvent extract, highest inhibition was observed in C.albicans of $80 \%$. Moderate inhibition of C.tropicalis by $46.4 \%$ and minimum inhibition of T.rubrum and P.marneffi by 46.15 and $45.8 \%$ respectively. Table (2), Fig 2

\section{Ethanol Extract P. kurroa Rhizome}

$5 \%$ rhizome solvent extract has shown highest inhibition of C.albicans by $65 \%$ followed by T.rubrum $23 \%$ and least was seen in C.tropicalis and P.marneffi by $21.4 \%$ and $20.8 \%$ respectively. However in $10 \%$ highest, inhibition was observed in C.albicans by $72.5 \%$ followed by P.marneffi $50 \%$ and minimum in C.tropicalis and T.rubrum by $46.4 \%$ and $38.46 \%$ respectively. Table(3), Fig 3.

Table.1 Growth of Mycelium (in millimeter) of Alcoholic Solvent Extracts of S. xantocarpum Root against the Test Fungal Organism by Poisoned Food Technique

\begin{tabular}{|l|l|l|l|}
\hline \multirow{2}{*}{$\begin{array}{l}\text { Fungal } \\
\text { Isolates }\end{array}$} & \multicolumn{3}{|l}{ S. xantocarpum root alcoholic extract } \\
\cline { 2 - 4 } Control & $\mathbf{5 \%}$ & $\mathbf{1 0 \%}$ \\
\hline C.albicans & 40 & $12 \mathrm{~mm}$ & $10 \mathrm{~mm}$ \\
\hline C.tropicalis & $28 \mathrm{~mm}$ & $19 \mathrm{~mm}$ & $15 \mathrm{~mm}$ \\
\hline T.rubrum & 13 & $11 \mathrm{~mm}$ & $7 \mathrm{~mm}$ \\
\hline P.marneffi & 24 & $18 \mathrm{~mm}$ & $16 \mathrm{~mm}$ \\
\hline
\end{tabular}


Table.2 Growth of Mycelium (in millimeter) of Alcoholic Solvent Extracts of S. xantocarpum Fruit against the Test Fungal Organism by Poisoned Food Technique

\begin{tabular}{|l|l|l|l|}
\hline \multirow{2}{*}{$\begin{array}{l}\text { Fungal } \\
\text { Isolates }\end{array}$} & \multicolumn{3}{|l|}{ S. xantocarpum fruit alcoholic extract } \\
\cline { 2 - 4 } Control & $\mathbf{5 \%}$ & $\mathbf{1 0 \%}$ \\
\hline C.albicans & 40 & $11 \mathrm{~mm}$ & $8 \mathrm{~mm}$ \\
\hline C.tropicalis & $28 \mathrm{~mm}$ & $20 \mathrm{~mm}$ & $15 \mathrm{~mm}$ \\
\hline T.rubrum & 13 & $8 \mathrm{~mm}$ & $7 \mathrm{~mm}$ \\
\hline P.marneffi & 24 & $14 \mathrm{~mm}$ & $13 \mathrm{~mm}$ \\
\hline
\end{tabular}

Table.3 Growth of Mycelium (in millimeter) of Alcoholic Solvent Extract of P. kurroa against the Test Fungal Organism by Poisoned Food Technique

\begin{tabular}{|l|l|l|l|}
\hline \multirow{2}{*}{$\begin{array}{l}\text { Fungal } \\
\text { Isolates }\end{array}$} & \multicolumn{3}{|c|}{ P. kurroa alcoholic extract } \\
\cline { 2 - 4 } Control & $\mathbf{5 \%}$ & $\mathbf{1 0 \%}$ \\
\hline C.albicans & 40 & $14 \mathrm{~mm}$ & $11 \mathrm{~mm}$ \\
\hline C.tropicalis & $28 \mathrm{~mm}$ & $18 \mathrm{~mm}$ & $15 \mathrm{~mm}$ \\
\hline T.rubrum & 13 & $10 \mathrm{~mm}$ & $8 \mathrm{~mm}$ \\
\hline P.marneffi & 24 & $19 \mathrm{~mm}$ & $12 \mathrm{~mm}$ \\
\hline
\end{tabular}

Fig.1a Antifungal Activity of S. xantocarpum Root

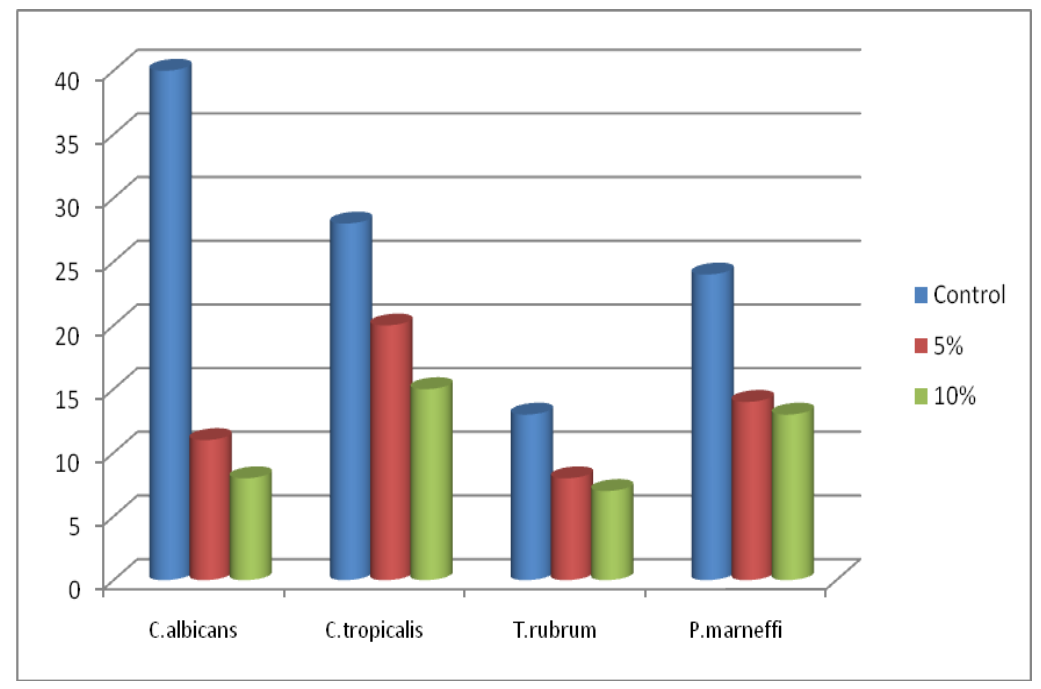


Fig.1b Antifungal Activity of S. xanthocarpum Root at 5\% and 10\% Alcoholic Extract
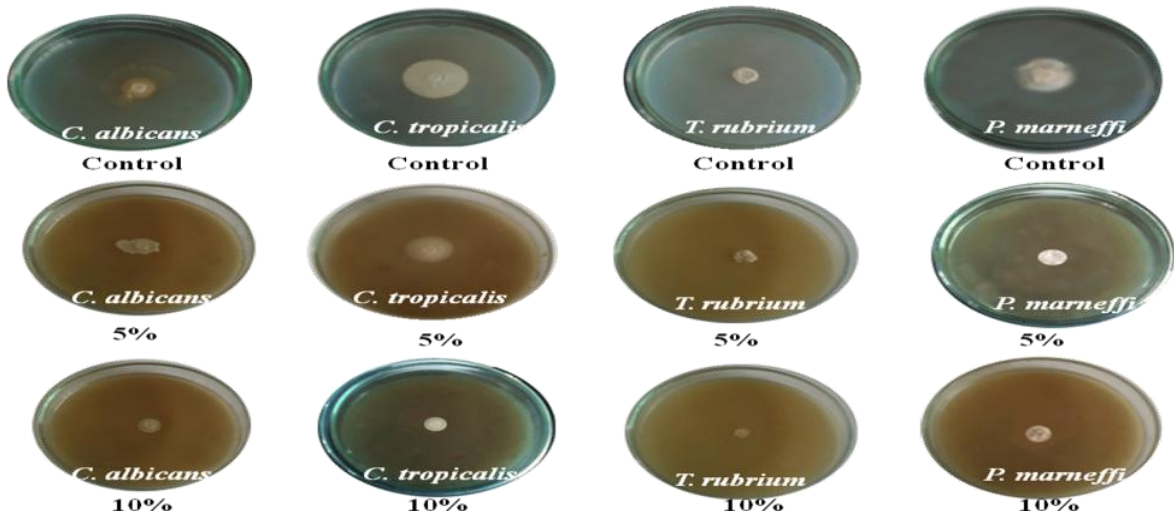

Control

Control
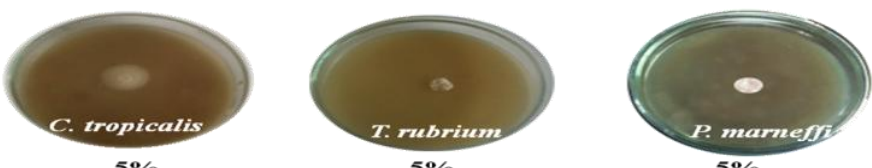

$5 \%$
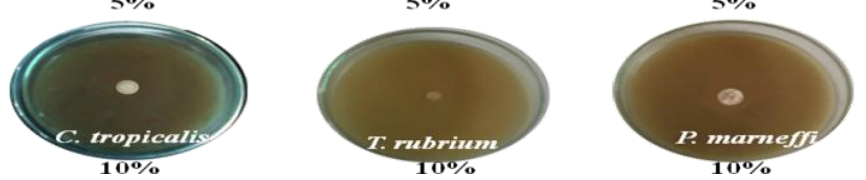

Fig.2a Antifungal Activity of S. xantocarpum Fruit

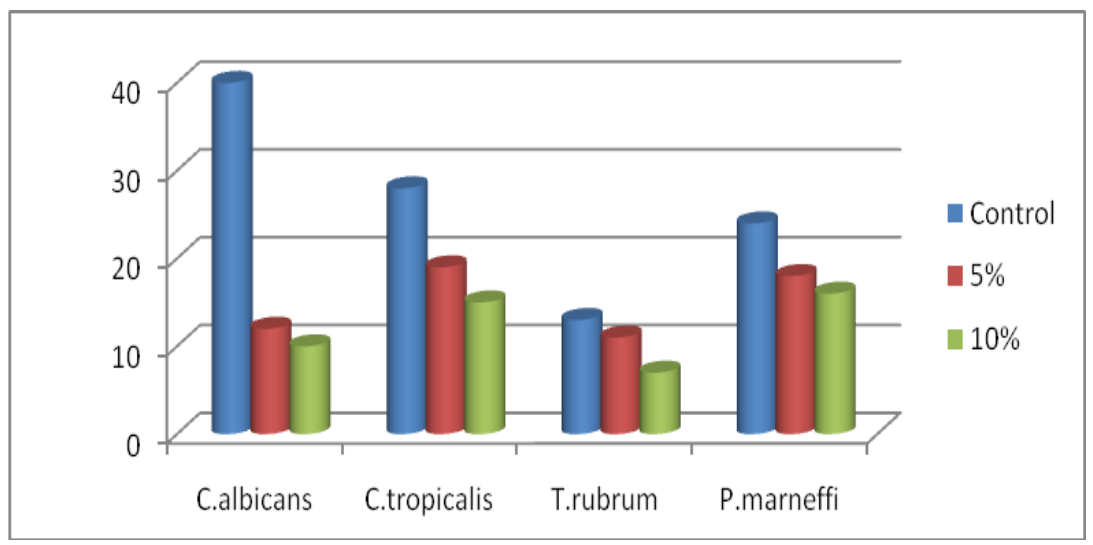

Fig.2b Antifungal Activity of S. xanthocarpum Fruit at 5\% and 10\% Alcoholic Extract

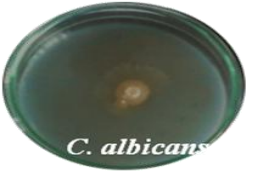

Control

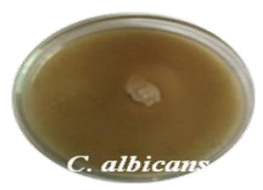

$5 \%$

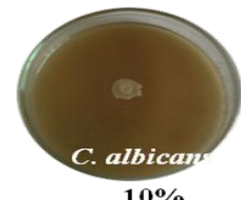

$10 \%$
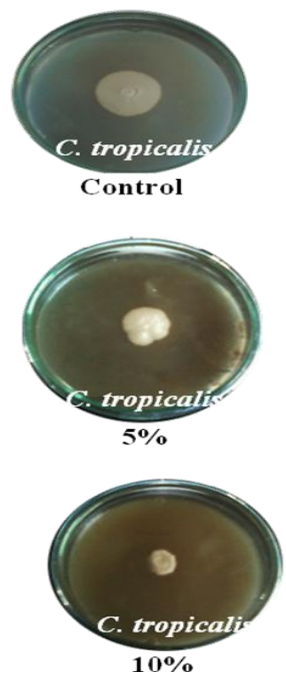

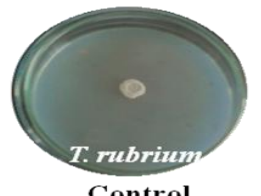

Control
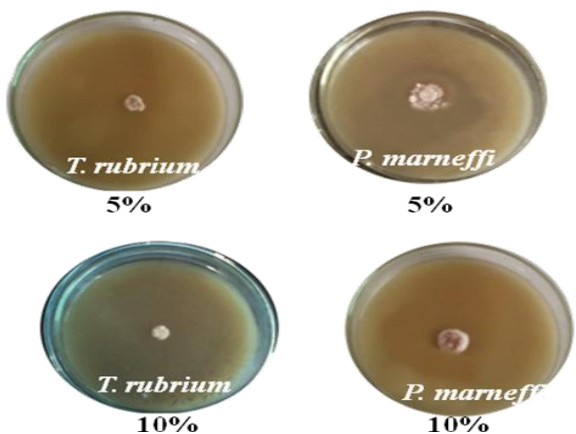
Fig.3a Antifungal Activity of $P$. kurroa

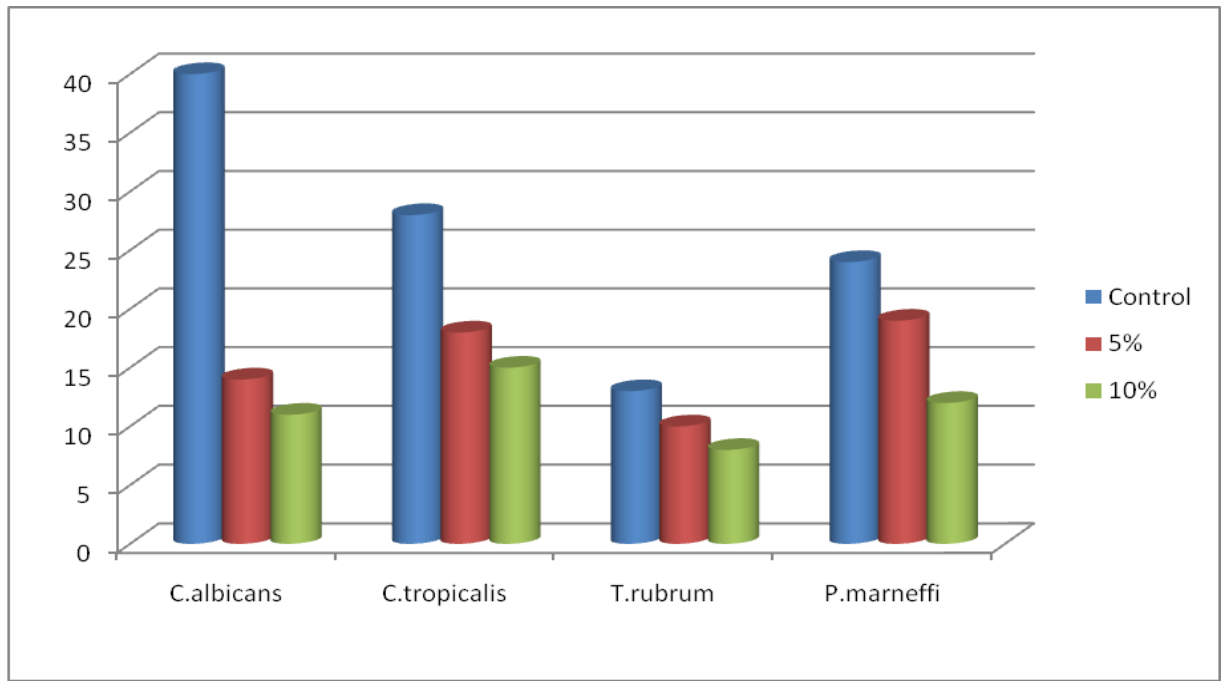

Fig.3b Antifungal Activity of $P$. kurroa Rhizome at 5 and 10\% Alcoholic Extract
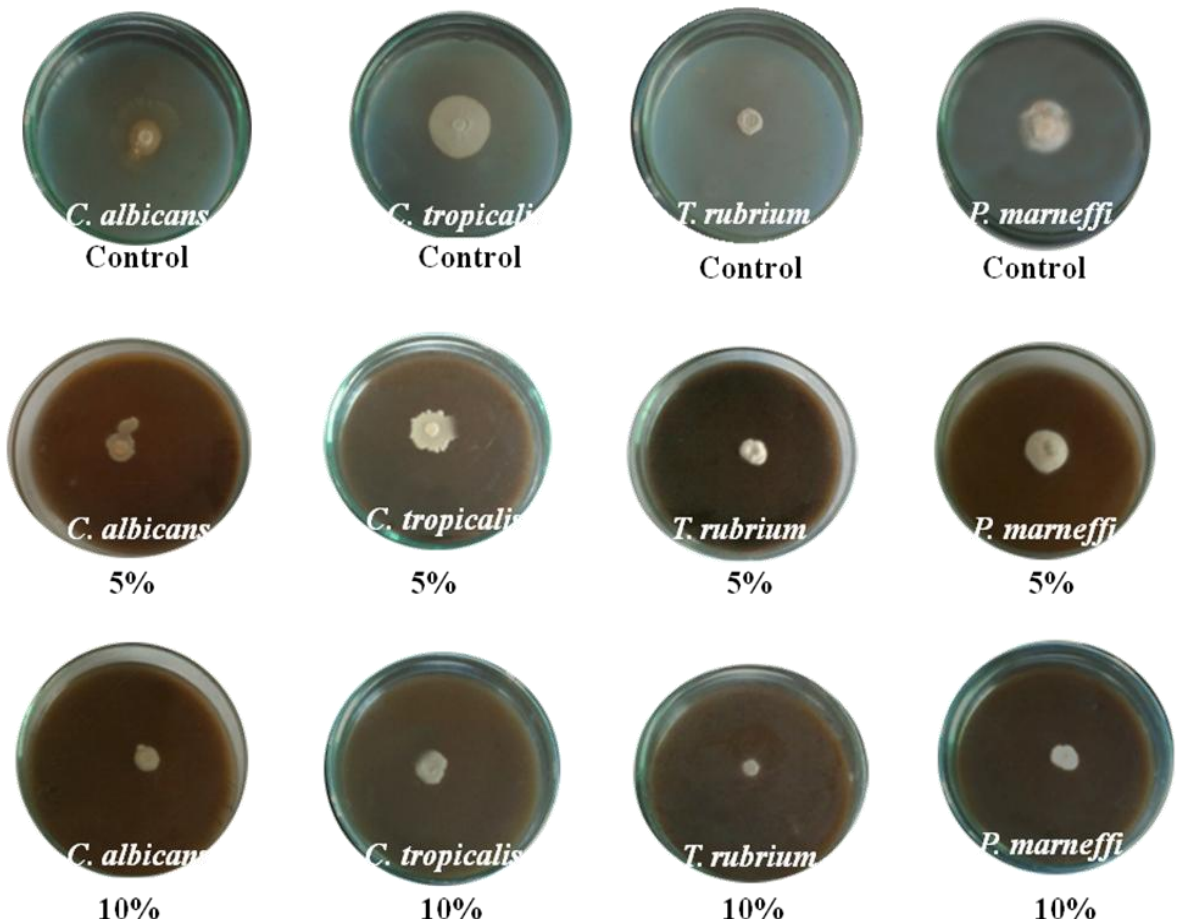

S. xantocarpum is an herb used in Indian medicinal system which is known to have repellent and antipyretic property. The dry fruit of $S$. xantocarpum contains isochlorgenic, neochromogenic, chromogenicaffic and acid (source: WWW.

Herbalcure india. Com/ herbs/ solanum). The other plants part contains coumarins, scpotetin, scoplin, scopoletin, esculin and esculetin. The chemical component lupeol, solamargine, apigenine (Chaturvedi et al., 2008., Siddiqui et al., 2008., Kuo et al., 
2000) are known to have anticancer property. The fruit extract has antifungal activity against Alternaria sps, Aspergillus sps, Trichoderma sps (Guleriaa et al, 2010; Singh et al, 2007; Dabur et al, 2004). Research related to the antifungal activity of the fruit and root against of $S$. xantocarpum many fungi namely Alternaria, Aspergillus spp and Trichoderma has been carried out by researchers and were successful in estimating the antifungal activity (Salar and Suchitra, 2009). In our study the alcoholic extract of $S$. xantocarpum fruit has exhibited the maximum inhibition of $C$. albicans (80\%), C. tropicalis (46.4\%), T.rubrum (48.15\%), and P.marneffi (45.8\%). Alcoholic root extract $(10 \%)$ of $S$. xantocarpum effective in inhibiting the dermatophytic clinical fungal isolates namely $C$. albicans by $75 \%$ followed by $C$. tropicalis (46.4\%), T.rubrum (46.2\%) and P.marneffi (33.3\%).

Previous studies of antifungal activity of $P$. kurroa has been demonstrated against $A$. niger and $C$. albicans by was tested by Mandloi et al., (2010) and Tiwari et al., (2011) and found that it plays a significant role in suppressing the fungi. According to the earlier reports that $P$. kurroa has a phenolic compound which may act as antifungal agent (Kokubun and Harborne., 1995; Aoyama et al., 1997). Similarly 10\% alcoholic extract has exhibited $72.5 \%$ inhibition of clinical isolates of $C$. albicans. This was followed by P.marneffi $(50 \%), C$. tropicalis (46.4\%) and T.rubrum (38.46\%).

In conclusion, $C$. albicans has showed susceptibility to the plant extracts compared to $C$. tropicalis, T.rubrum and P.marneffi tested. In the present study the alcoholic extract of $S$. xantocarpum fruit has shown $80 \%$ inhibition at $10 \%$ concentration indicates the effectiveness of the extract against the pathogen. All the other fungi have showed varied inhibition percentages against the plant extract. Comparatively, $10 \%$ of the extracts have shown inhibition than $5 \%$ extracts.

\section{References}

Aoyama, M., Mori, M., Okumura, M., Doi, S., Anetai, M. (1997) Antifungal activity of 2',6'- dihydroxy-4'methoxyacetophenone and related compounds. Mokuzai Gakkaishi (J. Wood Res. Soc.) 43, 108-111.

Chaturvedi, P. K., Bhui, K., Shukla, Y., Lupeol (2008). Connotations for chemoprevention. Cancer Lett. 263: $1-13$.

Dabur, R., Singh, H., Chhillar, A. K., Ali, M., Sharma, G. L (2004). Antifungal potential of Indian medicinal plants. Fitoterapia. 75(3-4): 389-391.

Dubey, R., Dubey, K., Sridhar, C., Jayaveere, K. N (2011). Human Vaginal Pathogen inhibition studies on aqueous, Methanolic and saponins extracts of steam barks of Ziziphus Mauritiana. Int. J. Pharm. Sci. Res. 2(3): 659-663.

Fostel, J., Lartey, P (2000). Emerging novel antifungal agents. Drug Discovery Today. 5: 25-32.

Giordani, R., Trebaux, J., Masi, M., Regli, P (2001). Enhanced antifungal activity of ketoconazole by Euphorbia characias latex against Candida albicans. Journal of Ethanopharmacology. 78: 1-5.

Guleriaa, S., Kumarb, A., Tikua., A. K (2010). Toxicity of Solanum xanthocarpum fruit extract against Alternaria brassicae, causal agent of Alternaria blight of Indian mustard (Brassica juncea). Arch Phytopathol Pl Protection . 43(3): 283-289.

Hussain, H., Badawy, A., Elshazly, A., Elsayed, A., Krohn, K., Riaz, M., 
Schulz, B (2011). Chemical constituents and antimicrobial activity of Salix subserrata. Rec. Nat. Prod. 5(2): 133-137.

Ignacimuthu, S., Ayyanar, M., Sankarasivaraman, K (2008). Ethanobotanical study of medicinal plants used by Paliyar tribals in $\mathrm{T}$ heni district of Tamil Nadu, India. Fitoterapia. 79: 562-568.

Kamali, HH EL., Amir MYEL (2010). Antibacterial activity and phytochemical screening of ethanolic extracts obtained from selected Sudanese medicinal plants. Curr. Res. J. of Bio. Sci. 2(2): 143-146.

Khan, N. H., M.S.A. Nur-E, Kamal, Rahman (1988). Antibacterial activity of Euphorbia thymifolia Linn. Indian. J. Med. Res. 87: 395397.

Kokubun, T., Harborne, J.B. (1995) Phytoalexin induction in the sapwood of plants of the maloideae (Rosaceae): biphenyls or dibenzofurans. Phytochemistry 40, 1649-1654.

Kuo, K. W., Hsu, H.H., Li, Y. P., Lin, W. L., Liu, L. F., Chang, L. C., Lin, C. C., Lin, C. N., Sheu, H. M (2000). Anticancer activity evaluation of the Solanum glycoalkaloid solamargine: Triggering apoptosis in human hepatoma cells. Biochem Pharmacol. 60: 1865-1873.

Lalitha, P., Arathi, K. A., Shubashini. K, Sripathi, Hemalath, S., Jayanthi, P (2010). Antimicrobial activity and phytochemical screening of an ornamental foliage plant. Pothos aurea (Linden ex Andre). An Int. J. of Chem. 1(2): 63-71.

Mandloi, D., Agrawal, a., Goyal, S., Wadhwa, S., Patel, r., Rawal, H. (2010).Antifungal potential of alcoholic extract of Picrochiza kurroa. Pharmacologyonline. 3:882885.

Mnimh, A. C (1996). The encyclopedia of medicinal plants. Dorling Kindersley, London, 34.

Nene, Y. L. and Thapliyal, P. N (1979). Fungicides in plant Diseases Control, Oxford and IBH Publication House, New Delhi, P. 163.

Panda, T., Panda, R. N (2008). Ethnomedicinal plants used by tribes of Kalahandi district, Orissa. Indian Journal Tradit Know. 7: 242-249.

Prasad, P. R. C., Reddy, S. C., Raza, S. H., Dutt, C. B. S (2008). Short report (ethano) folklore medicinal plants of North Andaman islands, India. Fitoterapia. 79: 324-329.

Salar, R. K. and suchitra (2009). Evaluation of antimicrobial potential of different extracts of Solanum xanthocarpum Schard. And Wendl. African journal of microbiology research. Vol 3(3). 97-100.

Siddiqui, Y. H., Beg, T., Afzal, M (2008). Antigenotoxic effect of apigenin against anti-cancererous drugs. Toxicology in Vitro. 22: 625-631.

Singh, A., Singh, P. K (2009). An ethanobotanical study of medicinal plants in Chandauli district of Uttar Pradesh, India. Journal of Ethanopharmacol. 79: 324-329.

Singh, O. M., Subharani, K., Singh, N. I., Devi, N. B., Nevidita, L (2007). Isolation of steroidal glycosides from Solanum xanthocarpum and studies on their antifungal activities. Nad Prod Res. 21(7): 585-590.

Tuley, De Silva, Theeshan Bahorun, Manoranjan Sahu, Le Mai Huong. Traditional and alternative medicines, research and policy Perspectives. Delhi: Daya Publishing House; 2009.

Tiwari, P., Kumar, B., Kaur, M., Kaur, H., 
Kaur, G. (2011). Phytochemical screening and extraction: A review. International Pharmaceutia ScienceVol 1, Issue, 98-106.

Vincent, J. M (1927). Distortion of fungal Hyphae in the presence of certain inhibitors. Nature. 59: 850.

WHO. (1998). The World Health report. Life in the $21^{\text {st }}$ century: a vision for all, 2. Measuring health. World Health Organization, Geneva, Switzerland, pp. 39-60.

WHO. Fact sheet N' 134 [Online]. Available from: http:// who.int/mediacntre/facts/fs134/en/ [Accessed on December 2008].

Yadav, J. P., Kumar, S (2003). Folk medicinal uses of some indigenous plants among the people of Mahendergarh District, Haryana, India. Plant Arch. 3(1): 37-43.

WWW. Herbalcure india. Com/ herbs/ solanum.

\section{How to cite this article:}

Shubha, K. S., K. Sumana and Lakshmidevi, L. 2016. Antifungal Activity of Solanum xantocarpum Sch and Wend and Picrorhiza kurroa Royle ex Benth against Some Clinical Dermatophytes. Int.J.Curr.Microbiol.App.Sci. 5(2): 236-244. doi: http://dx.doi.org/10.20546/ijcmas.2016.502.026 